\title{
Biological components in a standardized derivative of bovine colostrum
}

\author{
P. Sacerdote, ${ }^{*}$ F. Mussano,† S. Franchi, ${ }^{*}$ A. E. Panerai, ${ }^{*}$ G. Bussolati, S. Carossa,† A. Bartorelli,† \\ and B. Bussolati $\S^{1}$ \\ *Dipartimento di Scienze Farmacologiche e Biomolecolari, Università degli Studi di Milano, 20129 Milan, Italy \\ †Dipartimento di Scienze Biomediche ed Oncologia Umana, Università degli Studi di Torino, 10126 Turin, Italy \\ †lmmunologia Clinica, Università degli Studi di Milano, 20129 Milan, Italy \\ $\S$ Dipartimento di Medicina Interna, Università degli Studi di Torino, 10126 Turin, Italy
}

\begin{abstract}
Products of different origin, time of collection, and activities fall under the general term of colostrum and, therefore, great variability in composition as well as in the concentration of its components has been reported in the literature. In the present study, we describe the standardization of a bovine colostrum derivative and the characterization of its bioactive components. Evaluation of the most representative agents (lactoferrin, transferrin, IL-2, IFN- $\gamma$, tumor necrosis factor, $\operatorname{IgG}$, and $\operatorname{Ig} \mathrm{A}$ ) showed that a marked decrease in active components occurs after the first few hours. Bovine colostrum was, therefore, collected up to the fifth hour after delivery from Holstein cows, in the presence of preservatives, and immediately frozen. A protocol of centrifugation, filtration, and lyophilization was then applied to pools of colostrum from at least 30 cows to obtain a stable, sterile, standardized product. Preservatives were removed by dialysis. Evaluation of the active biological components of colostrum showed that the final product of colostrums contained significant and reproducible amounts of bioactive factors, including cytokines, immunomodulating factors, growth factors, and immunoglobulins. The final product appeared, therefore, as a sterile, pyrogen-free, standardized derivative of bovine colostrum with a high concentration of bioactive components.
\end{abstract}

Key words: colostrum, cytokine, growth factor, standardized product

\section{INTRODUCTION}

Colostrum and its beneficial effects have been well known for centuries, but only in recent times have studies analyzed the biological components responsible for its unique activities (Burrin et al., 1997; Koletzko et al., 1998). Colostrum properties include effects on protec-

Received July 11, 2012.

Accepted November 26, 2012.

${ }^{1}$ Corresponding author: benedetta.bussolati@unito.it tion and maturation of the gastrointestinal tract (Blum and Hammon, 2000a; Walker, 2010). Also, it mediates the transfer of the mother's defenses to the baby, which are not only due to immunoglobulins (Ogra and Ogra 1978; Jochims et al., 1994; Tyler et al., 1999), but also to factors of the innate system (Mata and Wyatt, 1971; Goldman and Smith, 1973; Moro et al., 1985; Blum and Hammon, 2000b; Kelly and Coutts, 2000; Solomons 2002). Moreover, colostrum or its components have been proposed as adjuvant agents in the treatment of chronic infections (Pammi and Haque, 2011; Elfstrand and Florén, 2010), diabetes (Kim et al., 2009), colitis (Lissner et al., 1996; Warny et al., 1999) and wound healing (Leitzel et al., 1985; Doillon et al., 2011). These multiple effects are clearly related to the presence of a large variety of active factors, including heat-resistant immunoglobulins, micronutrients (Feeley et al., 1983; Casey et al., 1985; Arnaud and Favier, 1995; Mastroeni et al., 2006), nucleotides (Schlimme et al., 2000), and oligosaccharides (Gopal and Gill, 2000), along with cytokines and heat-labile growth factors (Nojiri et al., 2012; Patki et al., 2012), and complement and antibacterial factors (Korhonen et al., 2000; Hanel et al., 2003).

Products of different origin, time of collection, and activities fall under the general term of colostrum, so that great variability in composition of colostrum as well as in the concentration of the components themselves has been reported in the literature (Devillers et al., 2007; Farmer and Quesnel, 2009; Quesnel, 2011). This variability may depend on multiple factors, among them the quick fall of the concentration of active components during the hours and days following delivery/ birth and animal breeding (Senda et al., 2011; Abd El-Fattah et al., 2012). Therefore, differential time of collection, methods of collection, and treatment may account for these discrepancies, as products labeled as colostrum have been defined as collected after 12, 24, or $48 \mathrm{~h}$ or even 4 to $5 \mathrm{~d}$ postparturition.

The aim of the present study was to create a standardized product with the highest possible content in defined biological components. For this purpose, we 
thought necessary to standardize the starting material in terms of cow breed and timing of colostrum collection and storage after delivery. Once a common source for the starting product was established, we planned a proper assessment of this substance and standardization of its components as mandatory to propose it as a biological agent. Preliminary to such standardization was the evaluation of the biological components present in colostrum at different collection times. The following steps focused on the aim of obtaining, as a final product, a sterile, pyrogen-free, standardized derivative of bovine colostrum with the highest concentration of bioactive factors. We describe here the processing procedure and the characteristics of such a product.

\section{MATERIALS AND METHODS}

\section{Colostrum Collection at Different Hours After Parturition}

Bovine colostrum was collected from Holstein cows at their second or third delivery at different time points (from 1 up to $12 \mathrm{~h}$ ) after parturition. At each time point, samples were collected from the same cow. In the last $55 \mathrm{~d}$ of gestation, cows were fed, according to a traditional dry period, with DM (Unifeed vacche asciutte, an integrated mix containing wheat and corn silage mix plus $25.7 \%$ row proteins and $2.4 \%$ row fats) produced by Consorzio Agrario di Cremona (Cremona, Italy). Colostrum was collected in 50-mL tubes that were centrifuged at $500 \times g$ for $20 \mathrm{~min}$ to remove the cream layer. The aqueous phase of these whey samples was collected and stored at $-20^{\circ} \mathrm{C}$ until ELISA analysis.

\section{Standardized Bovine Colostrum Derivative Preparation}

The colostrum collected from the first to the fifth hour after parturition (see below) was kept in 3-L containers with or without preservatives (phenoxyethanol $2.5 \%$ and diazolidinyl urea $1 \%$ ) that were immediately stored at $-20^{\circ} \mathrm{C}$. The extraction process was performed on stocks of $100 \mathrm{~L}$ for each preparation, to reduce individual variability, as described in the following steps (Figure 1). Colostrum was first diluted 1:10 in deionized water. Sodium chloride (Sigma-Aldrich, St. Louis, MO) was added to reach $0.9 \%$ concentration. The suspension was then centrifuged at $12,400 \times$ $g$ at 20 to $25^{\circ} \mathrm{C}$ and the pellet containing the lipidic phase was discarded. The supernatant was UF through a ceramic membrane with a $300-\mathrm{kDa}$ cutoff at 20 to $25^{\circ} \mathrm{C}$ and then dialyzed with a 5 -kDa polyethersulfone membrane (Sigma-Aldrich) to remove the preservatives as assessed by HPLC. Briefly, for each preservative, a limit of detectability and a limit of quantification were determined. A Simmetry column $(\mathrm{C} 18 ; 250 \times 4.6 \mathrm{~mm}$; 5 -mm film thickness; Waters Corp., Milford, MA) was used at room temperature, the flux being $0.8 \mathrm{~mL} / \mathrm{min}$. The product was then filtered under vacuum through regenerated cellulose 0.2- $\mu \mathrm{m}$ filters (Millipore, Billerica, $\mathrm{MA}$ ) and then frozen at $-20^{\circ} \mathrm{C}$ and lyophilized.

\section{Bacteriological Analysis}

Bacteriologic testing was performed on both colostrum and standardized bovine colostrum derivative (SBCD). Colostrum, collected in 3-L containers with preservatives (phenoxyethanol $2.5 \%$ and diazolidinyl urea $1 \%$ ), was immediately stored at $-20^{\circ} \mathrm{C}$. The samples were thawed and immediately transferred to sterile plastic tubes, following a published protocol (Fecteau et al., 2002). In selected experiments, preservatives were added only after thawing. One 1:10 dilution of each specimen (10 g) was prepared using sterile peptone physiological salt solution ( $\mathrm{pH} 7)$. For each dilution, $10 \mu \mathrm{L}$ was plated onto Trypticase soy agar (Difco Laboratories Inc., Detroit, MI) with $5 \%$ bovine blood. The plates were incubated at $37^{\circ} \mathrm{C}$ in an atmosphere of $5 \% \mathrm{CO}_{2}$. After $24 \mathrm{~h}$ of incubation, the different colony types were counted. In the absence of bacterial growth, plates were incubated for another 24 to $48 \mathrm{~h}$. Bacteriologic testing was performed following the same protocol on the lyophilized SBCD product $(10 \mathrm{~g}$ in 90 $\mathrm{mL}$ sterile peptone physiological salt solution, $\mathrm{pH} 7$ ). Bacterial counts were expressed as colony-forming units per gram of colostrum or SBCD. A Limulus amebocyte lysate test (Thermo Scientific, Rockford, IL) was performed according to the manufacture's instructions to evaluate the absence of endotoxins in colostrum and in the final product. A dichotomic outcome $(+/-)$ was reported, where the positive value $(+)$ corresponded to $\geq 0.4$ units per milliliter by ELISA.

\section{Detection of Cytokines and Bioactive Substances by ELISA}

The concentrations of lactoferrin, transferrin, IL-2, tumor necrosis factor (TNF), INF- $\gamma$, IgA, and IgG were determined using commercially available sandwich ELISA specific for bovine molecules. The cytokines IL2 , TNF, and IFN- $\gamma$ were measured with bovine kits purchased from R\&D Systems (Space Import Export s.r.l., Milan, Italy), whereas lactoferrin, transferrin, IgG, and IgA kits were obtained from Bethyl Laboratories (Tema Ricerca s.r.l., Bologna, Italy). All procedures were performed according to the instructions of the manufacturer. The sensitivity of the method was $125 \mathrm{pg} / \mathrm{mL}$ for IL-2, TNF, and IFN- $\gamma ; 7.8 \mathrm{ng} / \mathrm{mL}$ for 


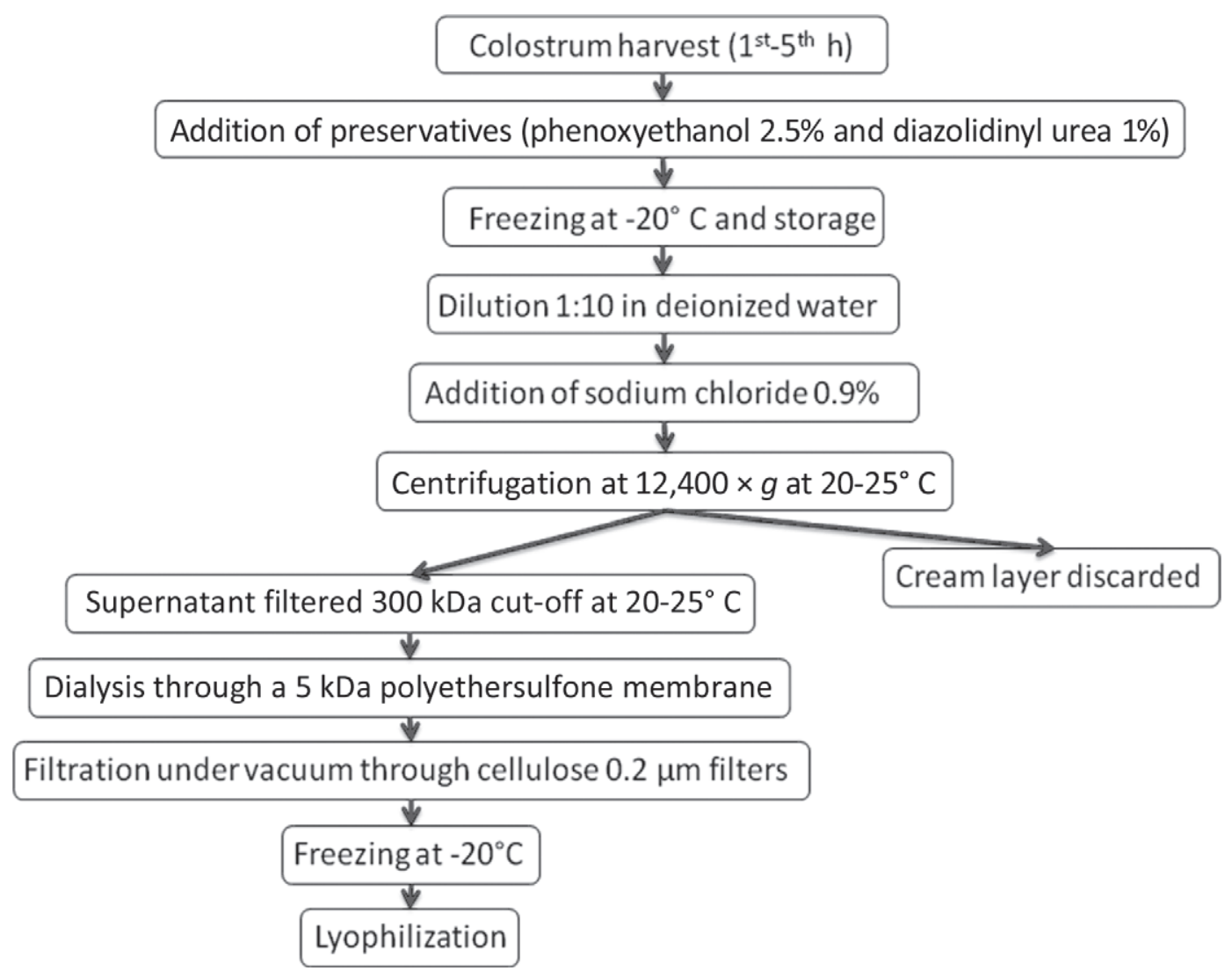

Figure 1. Schematic representation of the different passages in the process of standardized bovine colostrum derivative (SBCD) generation.

lactoferrin and $\mathrm{IgG} ; 3.9 \mathrm{ng} / \mathrm{mL}$ for transferrin; and $15.62 \mathrm{ng} / \mathrm{mL}$ for $\operatorname{IgA}$.

In a series of preliminary experiments, we identified for each substance the dilution needed to extrapolate the sample concentrations from the central part of the standard curve that was generated for each set of samples. For transforming growth factor (TGF)- $\beta$ and IGF-1 evaluation, human kits were used (R\&D systems, Space Import Export s.r.l.) because, as reported in previous literature, full cross-reactivity with the bovine factors is present (Hammer et al., 2004; Purup et al., 2007). The measured concentrations of bioactive substances are expressed either as amount per milliliter of liquid colostrum or amount per milligram of lyophilized product.

\section{Detection of Interleukins and Growth Factors Using the Bio-Plex System}

The concentration of specific cytokines and a vast number of growth factors was measured using human kits, as full cross-reactivity with the bovine factors has been reported (Hammer et al., 2004; Purup et al., 2007). The flexible Bio-Plex system (Bio-Rad Laboratories Inc., Hercules, CA), which is based on a capture sandwich immunoassay, allowed for the simultaneous dosage of different biomolecules to be done in a single microplate well. Briefly, fluorescent-dyed microspheres (Luminex Corp., Austin, TX) were conjugated with a specific primary antibody and the secondary antibody was biotin-labeled. A streptavidin-biotin reaction was used to quantify the amount of the analytes and the fluorescent system was used to identify the analyte. These assays and the antibodies underwent rigorous optimization to ensure the highest degree of sensitivity, specificity, and reproducibility. All samples were analyzed following the manufacturer's protocol. At least 3 independent repetitions in duplicate were made per experimental condition type. Analyte concentrations were expressed in picograms per milliliter. A standard curve ranging, on average, from 0.15 to $3,700 \mathrm{pg} / \mathrm{mL}$ (high photomultiplier tube setting) was prepared and then fitted by Bio-Plex Manager software.

\section{RESULTS}

\section{Biological Factors in Colostrum Variation With Time From Delivery}

Colostrum was collected from Holstein cows at their second or third delivery, as preliminary experiments 
showed higher colostrum production in cows after the second delivery with respect to those at the first delivery (not shown). Figure 2 reports the evaluation of the most representative agents (lactoferrin, transferrin, cytokines, and immunoglobulins) measured in colostrum whey obtained from 4 cows at different hours after parturition. For all substances, the highest concentrations were measured in samples obtained in the first $4 \mathrm{~h}$ after delivery. The levels of lactoferrin and of the cytokine IFN- $\gamma$ remained constant in all samples overtime (Figure 2A and D). In contrast, a clear and significant decrease in the concentrations of transferrin (panel B), IL-2 (panel C), TNF- $\alpha$ (panel E), and IgA (panel F) started to be present in colostrum samples obtained $10 \mathrm{~h}$ after parturition. Immunoglobulin $\mathrm{G}$ levels decreased after $6 \mathrm{~h}$ (Figure $2 \mathrm{G}$ ). To have the maximum concentrations of bioactive substances in colostrum, for generation of the standardized colostrum product, colostrum was collected up to the fifth hour that followed parturition. The dry weight after lyophilization of whole colostrum collected in the first $5 \mathrm{~h}$ from delivery $(300 \pm 22 \mathrm{~g} / \mathrm{L} ; \mathrm{n}=8)$ was higher than the dry weight of colostrum collected after $24 \mathrm{~h}(175 \pm$ $25 \mathrm{~g} / \mathrm{L} ; \mathrm{n}=5)$.

\section{Production of SBCD}

Bacteriological analysis of whole colostrum before the process of SBCD preparation showed that addition of preservatives at colostrum harvest, and not after thawing (see details in Materials and Methods section), was able to reduce bacterial growth with a high efficacy compared with colostrum collected in the absence of preservatives (Table 1). Therefore, to minimize bacterial growth, colostrum was collected in the presence of preservatives and immediately frozen.

To obtain the SBCD, a purification process was set up consisting of different steps of centrifugation, microfiltration, dialysis, and lyophilization, as depicted in Figure 1. After removal of the lipids and casein by centrifugation and UF through ceramic membranes, 5 dialysis cycles were used to remove preservatives, as assessed by HPLC, which remained in the final product in low concentration (phenoxyethanol: $0.3 \mathrm{~g} / \mathrm{L}$, diazolidinyl urea: $0.5 \mathrm{~g} / \mathrm{L}$ ). At the end of the purification/ extraction processes (i.e., after the final filtration under vacuum through $0.2-\mu \mathrm{m}$ filters) we were able to obtain a product pooled from around 30 cows $(100 \mathrm{~L}$ of colostrums, $3 \mathrm{~L}$ from each cow) that was finally lyophilized.

The bacteriological analysis of the SBCD produced from colostrum with preservatives added at the harvest showed a complete lack of bacterial growth and, more importantly, the lack of pyrogenic product release within the SBCD, as assessed by negative Limulus amebocyte lysate assay (Table 1). Interestingly, the analysis of SBCD derived from colostrum collected in the absence of preservatives showed that the process of SBCD preparation reduced bacterial contamination with respect to the whole colostrum, possibly due to its filtration through $0.2-\mu \mathrm{m}$ filters. However, SBCD preparation did not remove pyrogens (Table 1 ).

\section{Bioactive Substances in SBCD}

All bioactive factors were measured in colostrum and in SBCD before and after lyophilization. Table 2 reports the amount of bioactive substances (transferrin, lactoferrin, cytokines, growth factors, and immunoglobulins) in the whole colostrums and in the final product obtained after all processes (dialysis and filtration), before lyophilization. All substances were still present in a relevant amount in the final filtered products before lyophilization, although variable loss is present for most substances (Table 2). Similarly, all substances were present at measurable levels in the lyophilized filtered product (Table 3). In addition, by using a Bio-Plex platform, we also measured the concentration of several cytokines and a vast number of growth factors that were shown to be present in the lyophilized product (Figure 3 ). Among growth factors, basic fibroblast growth factor, TGF- $\beta$, TNF- $\alpha$, and vascular endothelial growth factor, and among cytokines, IL-2 and IL-17 were the most represented (Figure $3 \mathrm{~A}$ and B). The different SBCD preparations tested showed comparable results.

\section{DISCUSSION}

Our project focused first on the identification of conditions allowing collection of samples with the highest content of biological components. The analysis of the best-known and most representative agents (lactoferrin, transferrin, IL-2, IFN- $\gamma$, TNF, IgG, and IgA) clearly show that a marked decrease in active components occurs after the first few hours. These data, partially confirming reports in the literature (Purup et al., 2007; Senda et al., 2011; Abd El-Fattah et al., 2012) provide a rational interpretation of the discrepancies in biological activity among commercially available nonstandardized products labeled as colostrum. In fact, the milking of the cows is usually performed twice per day; hence, the common harvest of commercial colostrums at 24, 48, and $72 \mathrm{~h}$. However, as reported in the present study, this entails a dramatic decrease in concentration of some of the most relevant components, such as lactoferrin, cytokines, and immunoglobulins, whereas we never observed an increase in these factors at later times. Therefore, to apply the proposed extraction and purification protocol, it is mandatory to start from the most 
A

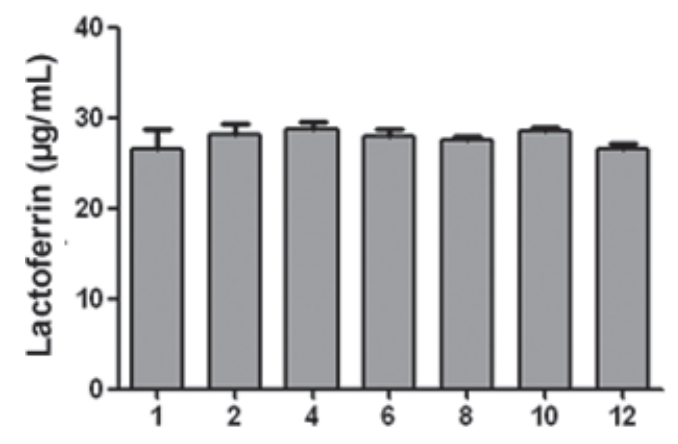

C

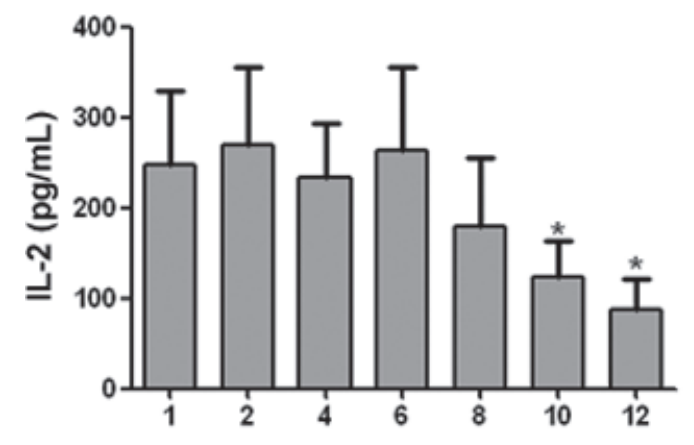

E

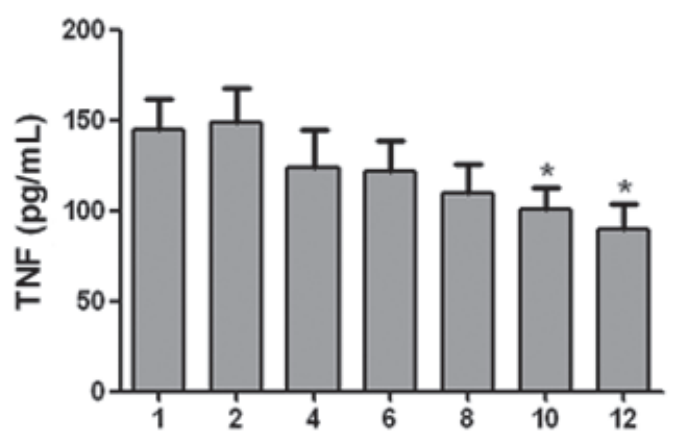

G

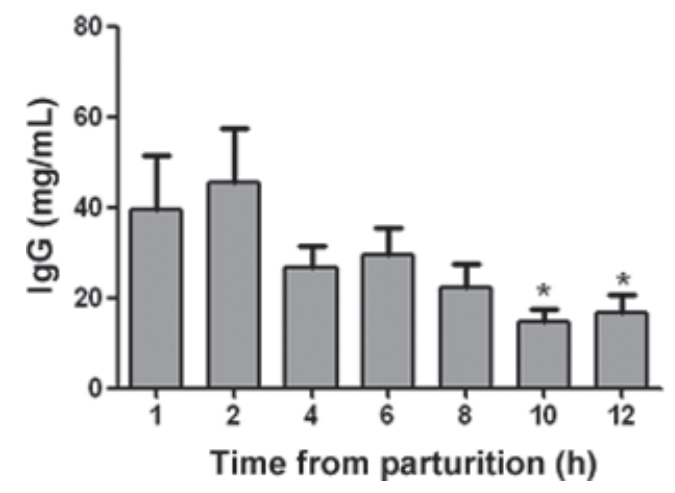

B
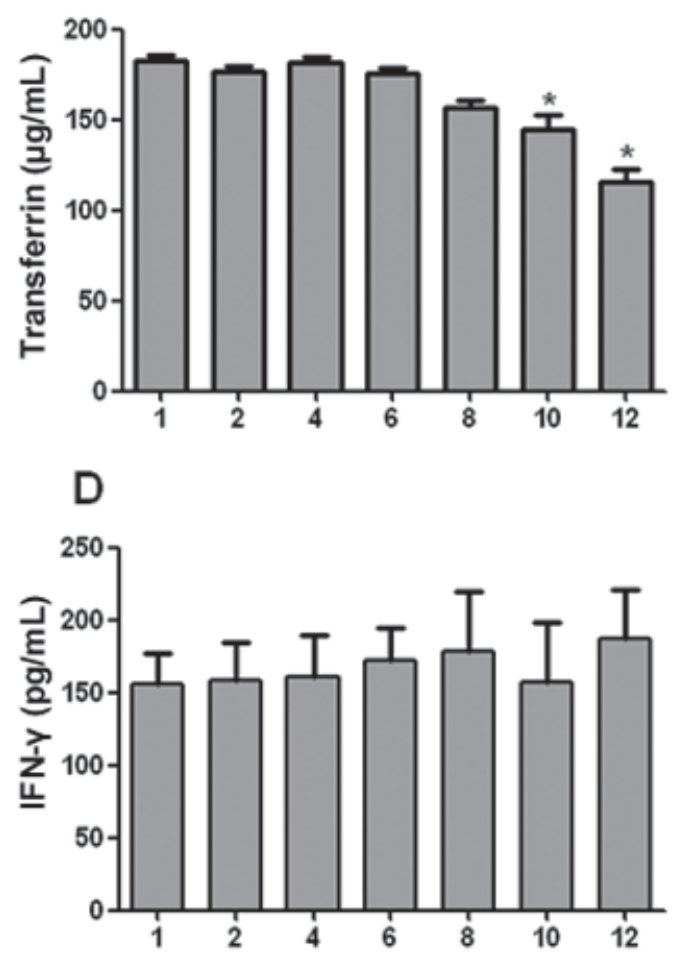

F

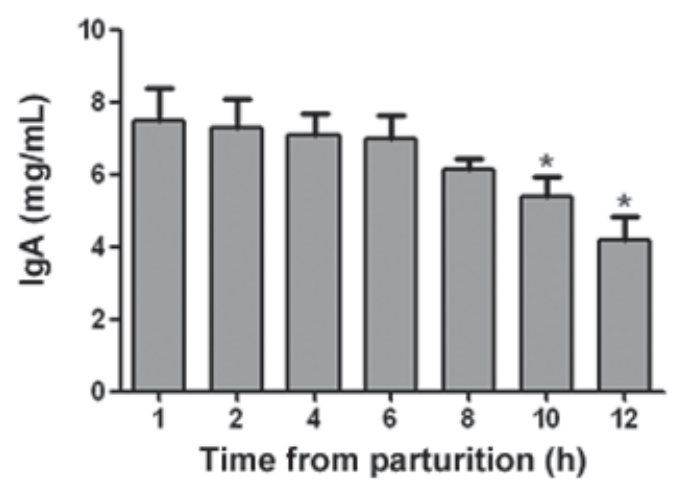

Figure 2. Evaluation of bioactive factors in the aqueous phase of colostrum collected at different time points after parturition. Data are means \pm SEM of colostrum collected from 4 different cows, each one at all the different hours. $t$-test: $* P<0.05$ versus colostrum collected at 1 , 2 , and $4 \mathrm{~h} . \mathrm{TNF}=$ tumor necrosis factor. 
Table 1. Bacterial count ( $\mathrm{cfu} / \mathrm{g}$ ), generated within $1 \mathrm{~g}$ of colostrum or standardized bovine colostrum derivative (SBCD; cfu/g), along with an Limulus amebocyte lysate (LAL) assay ${ }^{1}$

\begin{tabular}{llcc}
\hline Treatment $^{2}$ & Test & Colostrum & SBCD \\
\hline No preservatives & Bacterial count & $40 \times 10^{6}\left(28-67 \times 10^{6}\right)$ & $21.5(10-45)$ \\
& LAL & + & + \\
Preservatives added after thawing & Bacterial count & $33.2 \times 10^{6}\left(20-43 \times 10^{6}\right)$ & $\mathrm{ND}^{3}$ \\
& LAL & + & $\mathrm{ND}^{2}$ \\
Preservatives added at the harvest & Bacterial count & $245(45-350)$ & 0 \\
& LAL & - & - \\
\hline
\end{tabular}

${ }^{1}$ Data are means (range) of 4 different preparations.

${ }^{2}$ Colostrum was collected in the absence or presence of preservatives, stored at $-20^{\circ} \mathrm{C}$, and thawed; alternatively, preservatives were added after thawing. Standardized bovine colostrum derivative derived from colostrum collected in the absence or presence of preservatives was also tested.

${ }^{3} \mathrm{ND}=$ not done

concentrated colostrum, which is that of the first $5 \mathrm{~h}$. Moreover, if we consider that two-thirds of the product comprises immunoglobulins, the present protocol is the only one fit to ensure a considerable yield of biofactors.

The above considerations stress our planning and justify our decision to select the colostrum obtained between the first and the fifth hour as the source of choice for our product. Furthermore, we used a single type of cow (Holstein) and the source was colostrums after the second and third delivery, so as to guarantee a constant and abundant source of active biological components.

The second, and by no means minor, prerequisite of our goal was to end up with a sterile pyrogen-free product. This represented a particularly difficult task related to the harvesting conditions and was afforded with a 3 -faceted approach. First, the bacterial growth was blocked by collecting colostrum directly in the presence of preservatives. In fact, the complete depletion of the bacteria only at the end of the collection process does not ensure the absence of pyrogens (which once introduced, cannot be removed by any means). Moreover, bacterial growth would burn out and decrease the content of active biological components. The following step was that of UF, which ensured sterility by physically removing bacteria. The final process was linked to the elimination of preservatives by membrane dialysis.

At the end of the process, at our disposal, we had a stable, sterile, standardized product. Evaluation of the active biological components (see above) confirmed that we were still able to measure a relevant amount of components after the sterilization process. On the other hand, when we compared several different lots prepared according to the above sequence of procedures, similar values were obtained, thus confirming the achievement of our goal of a stable, standardized product (SBCD), which was finally preserved as a lyophilized powder. The low amount of residual preservative in SBCD potentially renders the product suitable for several therapeutic applications, such as in medical devices or for intradermal or subcutaneous administration. On the other hand, for nutritional application, the preparation of a SBCD product without preservatives might be considered in the future.

It is well known that colostrum, besides containing immunoglobulins, is rich in several bioactive substances. To assess the quality of the processes we used to achieve a final standardized product, we used as markers some colostrum key factors, such as lactoferrin and transferrin, which are present in high concentrations (Wheeler et al., 2007; Cheng et al., 2008). However, we also performed on the final SBCD product a search for a large number of bioactive factors. To our knowledge, this is the first study that simultaneously analyzed in the same bovine colostrum preparation such a large number of factors. This analysis was made possible by exploiting single classic ELISA tests along with an innovative soluble ELISA multiparametric method (Bio-Plex). As expected, the bioactive substances that we found in the SBCD can be roughly divided in 3 categories: antimicrobial peptides, cytokines, and growth factors. Although cytokines and growth factors are considered to be separate entities, it is important to appreciate that distinctions between them is sometimes blurred.

Lactoferrin and transferrin are involved in the regulation of iron metabolism and iron concentration, and their direct antimicrobial activity has been well characterized, with an activity exerted against a wide range of bacteria as well as viruses (Wheeler et al., 2007). Cytokines are small soluble proteins that act in an autocrine/paracrine fashion by binding to specific cellular receptors, operating in a network and orchestrating immune system development and function. Several cell types can produce cytokines: immune cells of innate and acquired immunity such as monocytes, macrophages, and $\mathrm{T}$ and $\mathrm{B}$ lymphocytes, and also nonimmune cells, including fibroblast and mammary epithelial cells (Wheeler et al., 2007). 
Table 2. Concentrations of bioactive substances measured in whole colostrum or in the final colostrum preparation after dialysis and filtration ${ }^{1}$

\begin{tabular}{|c|c|c|c|c|c|c|c|c|c|}
\hline Item & $\begin{array}{c}\text { Lactoferrin } \\
(\mu \mathrm{g} / \mathrm{mL})\end{array}$ & $\begin{array}{c}\text { Transferrin } \\
(\mu \mathrm{g} / \mathrm{mL})\end{array}$ & $\begin{array}{c}\mathrm{IL}-2 \\
(\mathrm{pg} / \mathrm{mL})\end{array}$ & $\begin{array}{c}\text { IFN- } \gamma \\
(\mathrm{pg} / \mathrm{mL})\end{array}$ & $\begin{array}{c}\text { TNF } \\
(\mathrm{pg} / \mathrm{mL})\end{array}$ & $\begin{array}{c}\mathrm{IgA} \\
(\mathrm{mg} / \mathrm{mL})\end{array}$ & $\begin{array}{c}\mathrm{IgG} \\
(\mathrm{mg} / \mathrm{mL})\end{array}$ & $\begin{array}{c}\text { TGF- } \beta \\
(\mathrm{pg} / \mathrm{mL})\end{array}$ & $\begin{array}{c}\text { IGF-1 } \\
(\mathrm{ng} / \mathrm{mL})\end{array}$ \\
\hline Whole colostrum & $34 \pm 7$ & $187 \pm 25$ & $190 \pm 3$ & $145 \pm 4$ & $245 \pm 52$ & $7 \pm 0.5$ & $41 \pm 2$ & $3,533 \pm 832$ & $170 \pm 70$ \\
\hline Filtered product & $28 \pm 8$ & $41 \pm 6$ & $39 \pm 4$ & $85 \pm 5$ & $85 \pm 5$ & $1 \pm 0.5$ & $12 \pm 4$ & $1,206 \pm 349$ & $42 \pm 8$ \\
\hline
\end{tabular}

${ }^{1}$ The data reported are the means \pm SD obtained from 3 different preparations, each one derived from a mix of at least 30 cows to minimize individual animal variations. The measured concentrations are expressed as amount per milliliter of liquid product. TNF $=$ tumor necrosis factor; TGF $=$ transforming growth factor.

Table 3. Concentrations of bioactive substances measured in the standardized bovine colostrum derivative $(\mathrm{SBCD})^{1}$







Figure 3. Evaluation of growth factors (top) and cytokines (bottom) in the standardized bovine colostrum derivative (SBCD). Factors were measured using a Bio-Plex platform (Bio-Rad Laboratories Inc., Hercules, CA) and expressed as picograms per milligram of lyophilized product \pm SEM. Eight different preparations were tested. FGF $=$ fibroblast growth factor; TGF $=$ transforming growth factor; NGF $=$ nerve growth factor; PDGF = platelet-derived growth factor; TNF $=$ tumor necrosis factor; VEGF $=$ vascular endothelial growth factor; GM-CSF $=$ granulocyte-macrophage colony-stimulating factor; G-CSF = granulocyte colony-stimulating factor.

Cytokines act at picomolar concentrations, and evidence is accumulating that they are present in human and bovine colostrums in quantities that can exert in vivo effect on the newborn recipient (Hawkes et al., 1999). These considerations have been confirmed by experiments showing that bovine colostrums can modulate the activity of human immune cells in vitro (Biswas et al., 2007). Cytokines, either related to innate immunity, such as TNF, IL-1, monocyte chemoattractant protein 1, and IL-15, or regulating acquired immunity, such as IL-2, IL-4, IFN- $\gamma$, IL-9, and IL-17, are important components of the SBCD. Among the identified cytokines, IL-17, which is the signature cytokine for T helper 17 (Th17) cells, is present in high concentrations in SBCD. Interleukin 17 has been characterized for its multiple properties, as it has a critical role against bacterial and fungal infection and possesses relevant proinflammatory activity (Gaffen, 2011). Recently, IL-17 was shown to display a regulatory role in hematopoiesis, being involved in the modulation of both hematopoietic and mesenchymal stem cells (Krstic et al., 2012). We also measured high levels of IL-15, which induces proliferation of $\mathrm{T}, \mathrm{B}$, and natural killer (NK) cells, stimulating the immune system maturation, and has unique antitumor activity (Steel et al., 2012).

An important aspect to be underlined is the fact that the host immune response is a fine balance between pro- and antiinflammatory components, and manipulating these responses requires care (Leung et al., 2010; Valledor et al., 2010). Interestingly, both stimulatory proinflammatory (IL-1, TNF, IFN- $\gamma$, and IL-12; Valledor et al., 2010) as well as inhibitory antiinflammatory cytokines (IL-10, IL-1RA, and TGF- $\beta$; Leung et al., 2010; Yoshimura and Muto, 2011) were present 
in our final product (SBCD). Therefore, the use of this balanced product both in vitro and vivo should guarantee the avoidance of excessive stimulation/inhibition for fine regulation of immune responses.

Among the cytokines/growth factors measured in SBCD, granulocyte colony-stimulating factor and granulocyte-macrophage colony-stimulating factor are pivotal substances for the proliferation, maturation, and expansion of bone marrow progenitor cells, and their role as stem-cell stimulating factors is now clear (Metcalf, 2008). Also, several growth factors are present in SBCD, such as peptides belonging to the fibroblast growth factors (Itoh and Ornitz, 2011), insulin-like growth factors (Wiley, 2012) and plateletderived growth factors (Andrae et al., 2008). As the physiological role of these trophic factors in colostrum is to regulate cell proliferation and differentiation in the gastrointestinal mucosa of the newborn (Playford et al., 2000; Purup et al., 2007), they are likely to play a primary role as for the regenerative and reparative properties of colostrum in wound healing (Leitzel et al., 1985; Doillon et al., 2011).

\section{CONCLUSIONS}

We prepared a lyophilized colostrum derivative that maintained most of the bioactive factors that appear to be at the basis of its many nutritional, modulatory, or even therapeutic, applications.

\section{ACKNOWLEDGMENTS}

We thank Advances in Medicine (AIM, Bologna, IT) for providing colostrum.

\section{REFERENCES}

Abd El-Fattah, A. M., F. H. R. Abd Rabo, S. M. El-Dieb, and H. A. El-Kashef. 2012. Changes in composition of colostrum of Egyptian buffaloes and Holstein cows. BMC Vet. Res. 8:19.

Andrae, J., R. Gallini, and C. Betsholtz. 2008. Role of platelet-derived growth factors in physiology and medicine. Genes Dev. 22:12761312.

Arnaud, J., and A. Favier. 1995. Copper, iron, manganese and zinc contents in human colostrum and transitory milk of French women. Sci. Total Environ. 159:9-15.

Biswas, P., A. Vecchi, P. Mantegani, B. Mantelli, C. Fortis, and A. Lazzarin. 2007. Immunomodulatory effects of bovine colostrums in human peripheral blood mononuclear cells. New Microbiol. 30:447-454.

Blum, J. W., and H. Hammon. 2000a. Colostrum effects on the gastrointestinal tract, and on nutritional, endocrine and metabolic parameters in neonatal calves. Livest. Prod. Sci. 66:151-159.

Blum, J. W., and H. M. Hammon. 2000b. Bovine colostrum: More than just an immunoglobulin supplier. Schweiz. Arch. Tierheilkd. $142: 221-228$.

Burrin, D. G., T. A. Davis, S. Ebner, P. A. Schoknecht, M. L. Fiorotto, and P. J. Reeds. 1997. Colostrum enhances the nutritional stimulation of vital organ protein synthesis in neonatal pigs. J. Nutr. 127:1284-1289.
Casey, C. E., K. M. Hambidge, and M. C. Neville. 1985. Studies in human lactation: Zinc, copper, manganese and chromium in human milk in the first month of lactation. Am. J. Clin. Nutr. 41:1193-1200.

Cheng, J. B., J. Q. Wang, D. P. Bu, G. L. Liu, C. G. Zhang, and H. Y. Wei., LZhou, Y., and J. Z. Wang. 2008. Factors affecting the lactoferrin concentration in bovine milk. J. Dairy Sci. 91:970-976.

Devillers, N., C. Farmer, J. Le Dividich, and A. Prunier. 2007. Variability of colostrum yield and colostrum intake in pigs. Animal 1:1033-1041

Doillon, C. J., F. Lehance, L. J. Bordeleau, M. P. Laplante-Campbell, and R. Drouin. 2011. Modulatory effect of a complex fraction derived from colostrum on fibroblast contractibility and consequences on repair tissue. Int. Wound J. 8:280-290.

Elfstrand, L., and C. H. Florén. 2010. Management of chronic diarrhea in HIV-infected patients: Current treatment options, challenges and future directions. HIV AIDS (Auckl.) 2:219-224.

Farmer, C., and H. Quesnel. 2009. Nutritional, hormonal, and environmental effects on colostrum in sows. J. Anim. Sci. 87:56-64.

Fecteau, G., P. Baillargeon, R. Higgins, J. Paré, and M. Fortin. 2002. Bacterial contamination of colostrum fed to newborn calves in Quebec dairy herds. Can. Vet. J. 43:523-527.

Feeley, R. M., R. R. Eitenmiller, J. B. Jones Jr., and H. Barnhart. 1983. Copper, iron, and zinc contents of human milk at early stages of lactation. Am. J. Clin. Nutr. 37:443-448.

Gaffen, S. L. 2011. Recent advances in the IL-17 cytokine family. Curr. Opin. Immunol. 23:613-619.

Goldman, A. S., and C. W. Smith. 1973. Host resistance factors in human milk. J. Pediatr. 82:1082-1090.

Gopal, P. K., and H. S. Gill. 2000. Oligosaccharides and glycoconjugates in bovine milk and colostrum. Br. J. Nutr. 84:S69-S74.

Hammer, C. J., J. D. Quigley, L. Ribeiro, and H. D. Tyler. 2004. Characterization of a colostrum replacer and a colostrum supplement containing IgG concentrate and growth factors. J. Dairy Sci. 87:106-111.

Hanel, R. M., P. C. Crawford, J. Hernandez, N. A. Benson, and J. K. Levy. 2003. Neutrophil function and plasma opsonic capacity in colostrum-fed and colostrum-deprived neonatal kittens. Am. J. Vet. Res. 64:538-543.

Hawkes, J. S., D. L. Bryan, M. J. James, and R. A. Gibson. 1999. Cytokines (IL-1 $\beta$, IL-6 TNF $\alpha$, TGF $\beta 1$ and TGF $\beta 2$ ) and prostaglandin E2 in human milk during the first three months postpartum. Pediatr. Res. 46:194-199.

Itoh, N., and D. M. Ornitz. 2011. Fibroblast growth factors: From molecular evolution to roles in development, metabolism and disease. J. Biochem. 149:121-130.

Jochims, K., F.-J. Kaup, W. Drommer, and M. Pickel. 1994. An immunoelectron microscopic investigation of colostral IgG absorption across the intestine of newborn calves. Res. Vet. Sci. 57:75-80.

Kelly, D., and A. G. Coutts. 2000. Early nutrition and the development of immune function in the neonate. Proc. Nutr. Soc. 59:177-185.

Kim, J. H., W. S. Jung, N. J. Choi, D. O. Kim, D. H. Shin, and Y. J. Kim. 2009. Health-promoting effects of bovine colostrum in type 2 diabetic patients can reduce blood glucose, cholesterol, triglyceride and ketones. J. Nutr. Biochem. 20:298-303.

Koletzko, B., P. J. Aggett, J. G. Bindels, P. Bung. P. Ferré, A. Gil, M. J. Lentze, M. Roberfroid, and S. Strobel. 1998. Growth, development and differentiation: A functional food science approach. Br. J. Nutr. 80(Suppl. 1):S5-45.

Korhonen, H., P. Marnila, and H. S. Gill. 2000. Milk immunoglobulins and complement factors. Br. J. Nutr. 84(Suppl. 1):S75-S80.

Krstic, A., S. Mojsilovic, G. Jovcic, and D. Bugarski. 2012. The potential of interleukin-17 to mediate hematopoietic response. Immunol. Res. 52:34-41.

Leitzel, K., C. Cano, J. G. Marks Jr., and A. Lipton. 1985. Growth factors and wound healing in the hamster. J. Dermatol. Surg. Oncol. 11:617-622.

Leung, S., X. Liu, L. Fang, X. Chen, T. Guo, and J. Zhang. 2010. The cytokine milieu in the interplay of pathogenic Th1/Th17 cells and regulatory $\mathrm{T}$ cells in autoimmune disease. Cell. Mol. Immunol. $7: 182-189$. 
Lissner, R., H. Schmidt, and H. Karch. 1996. A standard immunoglobulin preparation produced from bovine colostra shows antibody reactivity and neutralization activity against Shiga-like toxins and EHEC-hemolysin of Escherichia coli O157:H7. Infection $24: 378-383$.

Mastroeni, S. S., I. A. Okada, P. H. Rondó, M. C. Duran, A. A. Paiva, and J. M. Neto. 2006. Concentrations of Fe, K, Na, Ca, P, Zn and $\mathrm{Mg}$ in maternal colostrum and mature milk. J. Trop. Pediatr. $52: 272-275$.

Mata, L. J., and R. G. Wyatt. 1971. The uniqueness of human milk. Host resistance to infection. Am. J. Clin. Nutr. 24:976-986.

Metcalf, D. 2008. Hematopoietic cytokines. Blood 111:485-491.

Moro, I., T. Abo, S. S. Crago, K. Komiyama, and J. Mestecky. 1985. Natural killer cells in human colostrum. Cell. Immunol. 93:467474 .

Nojiri, T., T. Yoshizato, T. Fukami, H. Obama, H. Yagi, F. Yotsumoto, and S. Miyamoto. 2012. Clinical significance of amphiregulin and epidermal growth factor in colostrum. Arch. Gynecol. Obstet. 286:643-647.

Ogra, S. S., and P. L. Ogra. 1978. Immunologic aspects of human colostrum and milk: I. Distribution characteristics and concentrations of immunoglobulins at different times after the onset of lactation. J. Pediatr. 92:546-549.

Pammi, M., and K. N. Haque. 2011. Oral immunoglobulin for the prevention of rotavirus infection in low birth weight infants. Cochrane Database Syst. Rev. 11:CD003740.

Patki, S., U. Patki, R. Patil, S. Indumathi, P. Kaingade, A. Bulbule, A. Nikam, and A. Pishte. 2012. Comparison of the levels of the growth factors in umbilical cord serum and human milk and its clinical significance. Cytokine 59:305-308.

Playford, R. J., C. R. Macdonald, and W. S. Johnson. 2000. Colostrum and milk-derived peptide growth factors for the treatment of gastrointestinal disorders. Am. J. Clin. Nutr. 72:5-14.

Purup, S., M. Vestergaard, L. O. Pedersen, and K. Sejrsen. 2007. Biological activity of bovine milk on proliferation of human intestinal cells. J. Dairy Res. 74:58-65.
Quesnel, H. 2011. Colostrum production by sows: Variability of colostrum yield and immunoglobulin G concentrations. Animal 5:1546-1553.

Schlimme, E., D. Martin, and H. Meisel. 2000. Nucleosides and nucleotides: natural bioactive substances in milk and colostrum. Br. J. Nutr. 84(Suppl. 1):S59-S68.

Senda, A., K. Fukuda, T. Ishii, and T. Urashima. 2011. Changes in the bovine whey proteome during the early lactation period. Anim. Sci. J. 82:698-706.

Solomons, N. W. 2002. Modulation of the immune system and the response against pathogens with bovine colostrum concentrates. Eur. J. Clin. Nutr. 56:S24-S28.

Steel, J. C., T. A. Waldmann, and J. C. Morris. 2012. Interleukin-15 biology and its therapeutic implications in cancer. Trends Pharmacol. Sci. 33:35-41.

Tyler, J. W., B. J. Steevens, D. E. Hostetler, J. M. Holle, and J. L. Denbigh Jr. 1999. Colostral immunoglobulin concentrations in Holstein and Guernsey cows. Am. J. Vet. Res. 60:1136-1139.

Valledor, A. F., M. Comalada, L. F. Santamaría-Babi, J. Lloberas, and A. Celada. 2010. Macrophage proinflammatory activation and deactivation: A question of balance. Adv. Immunol. 108:1-20.

Walker, A. 2010. Breast milk as the gold standard for protective nutrients. J. Pediatr. 156:S3-S7.

Warny, M., A. Fatimi, E. F. Bostwick, D. C. Laine, F. Lebel, J. T. LaMont, C. Pothoulakis, and C. P. Kelly. 1999. Bovine immunoglobulin concentrate-Clostridium difficile retains $C$ difficile toxin neutralising activity after passage through the human stomach and small intestine. Gut 44:212-217.

Wheeler, T. T., A. J. Hodgkinson, C. G. Prosser, and S. R. Davis 2007. Immune components of colostrum and milk-A historical perspective. J. Mammary Gland Biol. Neoplasia 12:237-247.

Wiley, A. S. 2012. Cow milk consumption, insulin-like growth factor-I, and human biology: A life history approach. Am. J. Hum. Biol $24: 130-138$.

Yoshimura, A., and G. Muto. 2011. TGF- $\beta$ function in immune suppression. Curr. Top. Microbiol. Immunol. 350:127-147. 